\title{
Cardiac sympathetic activity in hypertrophic cardiomyopathy and Tako-tsubo cardiomyopathy
}

\author{
Derk O. Verschure ${ }^{1,2} \cdot$ Berthe L. F. van Eck-Smit ${ }^{1} \cdot$ G. Aernout Somsen ${ }^{3}$ • \\ Hein J. Verberne ${ }^{1}$
}

Received: 1 July 2015 / Accepted: 22 July 2015/Published online: 4 August 2015

(C) The Author(s) 2015. This article is published with open access at Springerlink.com

\begin{abstract}
I-meta-iodobenzylguanidine $\quad\left({ }^{123} \mathrm{I}-m \mathrm{IBG}\right)$ scintigraphy has been established as an important technique to evaluate cardiac sympathetic function and it has been shown to be of clinical value, especially for the assessment of prognosis, in many cardiac diseases. The majority of ${ }^{123} \mathrm{I}-m \mathrm{IBG}$ scintigraphy studies have focused on patients with cardiac dysfunction due to hypertension, ischemic heart disease, or valvular disease. However less is known about the role of ${ }^{123}$ I- $m$ IBG scintigraphy in primary cardiomyopathies. This overview shows the clinical value of ${ }^{123}$ I- $m$ IBG scintigraphy in two types of primary cardiomyopathy: The genetic hypertrophic cardiomyopathy (HCM) and the acquired Tako-tsubo cardiomyopathy (TCM). Cardiac sympathetic activity is increased in HCM and correlates to the septal wall thickness and consequently to the LVOT obstruction. Moreover, increased cardiac sympathetic activity correlates with impaired diastolic and systolic LV function. In addition, ${ }^{123}$ I- $m$ IBG scintigraphy may be useful for determining the risk of developing congestive heart failure and ventricular tachycardia in these patients. In TCM ${ }^{123}$ I- $m$ IBG scintigraphy can be used to
\end{abstract}

Derk O. Verschure

d.o.verschure@amc.uva.nl

1 Department of Nuclear Medicine, Academic Medical Center, University of Amsterdam, P.O. Box 22700,

1100 DE Amsterdam, The Netherlands

2 Department of Cardiology, Medical Center Alkmaar, Alkmaar, The Netherlands

3 Cardiology Centers of the Netherlands, Amsterdam, The Netherlands assess cardiac sympathetic hyperactivity. In addition, ${ }^{123} \mathrm{I}-$ $m$ IBG scintigraphy may identify those patients who are prone to TCM recurrence and may help to identify responders to individual (pharmacological) therapy.

Keywords Cardiac sympathetic activity $\cdot{ }^{123}$ I-mIBG scintigraphy · Tako-tsubo cardiomyopathy · Hypertrophic cardiomyopathy

\section{Introduction}

The last decades, ${ }^{123} \mathrm{I}$-meta-iodobenzylguanidine $\left({ }^{123} \mathrm{I}-\right.$ $m$ IBG) scintigraphy has been established as an important technique to evaluate cardiac sympathetic function. $m$ IBG is a norepinephrine (NE) analog that has the same presynaptic uptake, storage and release mechanism as NE. Radiolabeling of $m \mathrm{IBG}$ with ${ }^{123} \mathrm{I}$ allows for imaging with gamma-cameras. Cardiac ${ }^{123} \mathrm{I}-m \mathrm{IBG}$ scintigraphy has been shown to be of clinical value, especially for the assessment of prognosis, in many cardiac diseases [1-5]. Both a decreased late heart to mediastinal ratio (late $\mathrm{H} / \mathrm{M}$ ) and an increased myocardial washout rate (WO) of ${ }^{123} \mathrm{I}-m \mathrm{IBG}$ are associated with a poor prognosis. The majority of ${ }^{123} \mathrm{I}$ $m$ IBG scintigraphy studies have focused on patients with cardiac dysfunction due to hypertension, ischemic heart disease, or valvular disease. In general, these studies include heterogeneous populations (e.g., ischemic and nonischemic). However less is known on the role of ${ }^{123} \mathrm{I}-\mathrm{mIBG}$ scintigraphy in primary cardiomyopathies (i.e., cardiomyopathies predominantly involving the myocardium). In this overview, we will discuss the clinical value of ${ }^{123} \mathrm{I}-\mathrm{mIBG}$ scintigraphy in two types of primary cardiomyopathy: The genetic hypertrophic cardiomyopathy (HCM) and the acquired Tako-tsubo cardiomyopathy (TCM). 


\section{Hypertrophic cardiomyopathy}

HCM, the most common of the genetic cardiovascular diseases, is caused by a multitude of mutations in genes encoding for proteins of the cardiac sarcomere. The prevalence of HCM is approximately 1:500 [6]. HCM is defined by a characteristic histopathogical appearance called myocyte disarray [7]. This disarray results in left ventricular hypertrophy with diastolic dysfunction. The prognosis of HCM has an inverse relation to the degree of hypertrophy [8]. Left ventricular outflow tract (LVOT) obstruction is present in 20-25\% of patients with HCM. This obstruction is caused by asymmetric septal myocardial hypertrophy (Fig. 1) [9, 10]. The severity of LVOT obstruction is correlated with impaired excise tolerance, heart failure and sudden cardiac death (SCD). In addition, myocardial fibrosis in HCM is a risk factor for lethal arrhythmias and SCD [11].

\section{Cardiac sympathetic activity and prognosis in HCM}

HCM involves impaired cardiac sympathetic innervation with impaired NE uptake resulting in increased spillover of NE with increased serum levels of NE [12-14]. Since the introduction of cardiac ${ }^{123} \mathrm{I}-m \mathrm{IBG}$ scintigraphy it has been reported that cardiac sympathetic activity in HCM is impaired (i.e., decreased late H/M and increased WO) [1518]. Some of these studies reported that WO correlates with the severity of hypertrophy $[15,16]$.

Pace et al. evaluated ${ }^{123} \mathrm{I}-m \mathrm{IBG}$ uptake and WO in relation to left ventricular (LV) function and perfusion [19]. Eleven patients with HCM were enrolled. All patients were subjected to planar and single photon emission computed tomography (SPECT) ${ }^{123}$ I- $m$ IBG scintigraphy, ${ }^{99 \mathrm{~m}}$ Tc-MIBI SPECT and echocardiography. WO showed a positive relation with LVOT obstruction $(r=0.84$, $p<0.001)$ and septum thickness $(r=0.76, p<0.01)$. These data suggest that cardiac sympathetic activity correlates to the degree of septal hypertrophy and consequently LVOT obstruction and diastolic function in HCM. On the other hand, late $\mathrm{H} / \mathrm{M}$ increases and consequently WO decreases in the months following septal ablation, a percutaneous procedure to induce a septal infarction which results in a reduction of LVOT obstruction [20].

LV function is usually normal at the onset of HCM. However, late in the disease dilatation and LV dysfunction can occur. In end-stage HCM LV dysfunction is related to thinning of the septal wall [21]. This septal thinning is histopathologically associated with extensive myocardial fibrosis [22]. Terai et al. studied the changes of WO from early to end-stage HCM. In this study 46 patients with $\mathrm{HCM}$ were enrolled and divided in three different stages of HCM: preserved LV function, dilated LV with preserved LV function and dilated LV with impaired LV function) [23]. Interestingly, regional early uptake was significantly reduced in the septal wall, predominately in the end-stage HCM. In addition, regional washout rate in this group was significantly increased in the apex and lateral wall. These findings could indicate that the development of LV systolic dysfunction caused by myocyte death and increased fibrosis in het septal wall leads to an increase cardiac sympathetic activity resulting in a further increase of WO. Decreased number of myocytes and increased fibrosis result in decreased early uptake of ${ }^{123} \mathrm{I}-m \mathrm{IBG}$ in the septal wall. In response to impaired cardiac function, cardiac sympathetic activity in het apex and lateral wall with viable myocytes increases to preserve LV function.

In line with this study Matsuo et al. reported that in 59 patients with HCM the brain natriuretic peptide (BNP), a marker of LV dysfunction or damage, and left ventricular mass index (LVMI) measured with echocardiography, were independent predictors of late $\mathrm{H} / \mathrm{M}(p=0.0001$ and
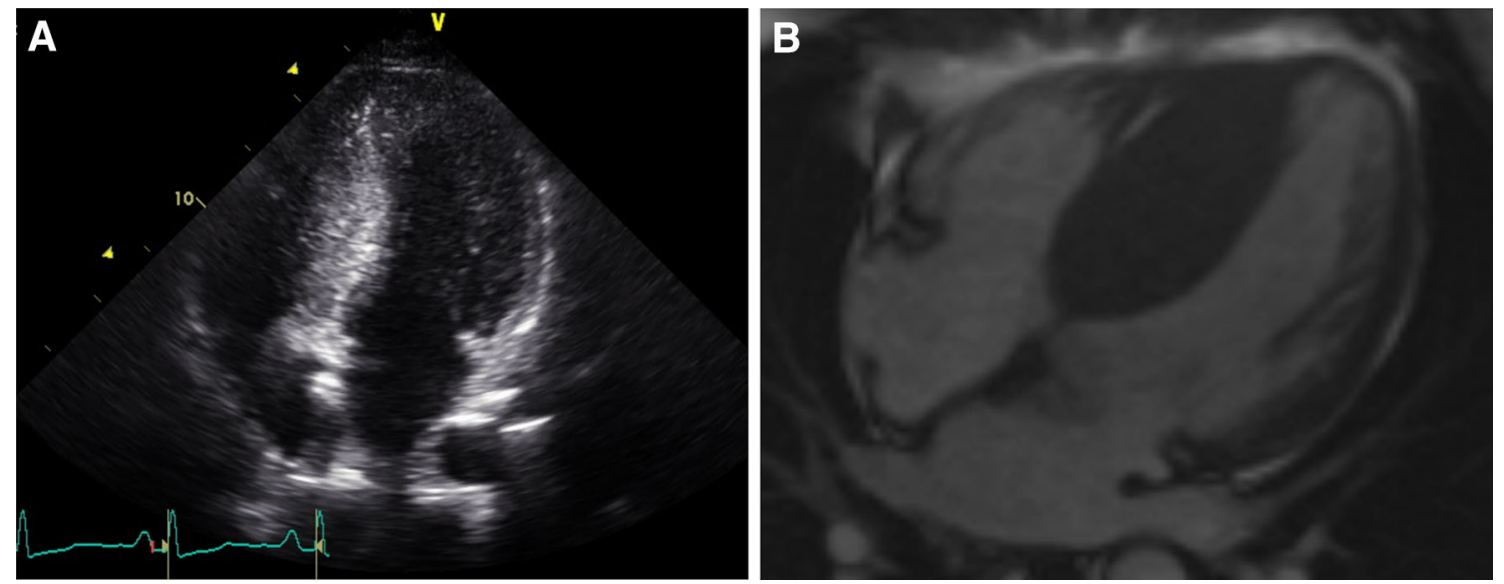

Fig. 1 Examples of hypertrophic cardiomyopathy assessed with echocardiography (a) and MRI (b) showing severe septal hypertrophy of the LV 
$p=0.0009$, respectively) [24]. In addition, NE serum level was an independent predictor of WO $(p=0.018)$. The negative correlation between late $\mathrm{H} / \mathrm{M}$ and $\mathrm{BNP}$ ( $r=-0.44, p<0.001)$, indicates that cardiac sympathetic neuronal dysfunction corresponds to the severity of HCM.

In patients with $\mathrm{HCM}$, congestive heart failure (CHF) caused by LV dilatation and dysfunction is an important determent as well as a predictor of SCD [25-27]. However, clinical tools for predicting the onset of CHF in HCM are limited. Hiase et al. demonstrated that cardiac sympathetic activity could be useful in predicting the onset of CHF in patients with HCM [28]. In this study 84 patients with HCM were enrolled. The prevalence of CHF during a follow-up of 9-86 months was $0 \%$ in patients with $\mathrm{H} / \mathrm{M}$ $>2.11,3.3 \%$ in patients with $\mathrm{H} / \mathrm{M}, 1.86$ to $<2.11$ and $55.0 \%$ in patients with $\mathrm{H} / \mathrm{M}<1.86$. Multivariate analysis showed that cardiac sympathetic activity, as reflected by the late $\mathrm{H} / \mathrm{M}$ and $\mathrm{LV}$ fractional shortening were significant predictors of CHF in HCM.

Since HCM is caused by various gene mutations, each mutation may give rise to a specific pathophysiological pathway which may also result in specific modulations of the sympathetic nervous system. In HCM caused by the Asp175Asn substitution of the alpha-tropomyosin gene (TPM1-Asp175Asn) there is a correlation between WO and LV hypertrophy measured by MRI $(r=0.512, p=0.018)$ [29]. Although these results are in line with the previous reported HCM population, it is unclear if these findings apply to other HCM gene mutations.

\section{Cardiac sympathetic activity and arrhythmias in $\mathrm{HCM}$}

SCD is a serious complication of HCM and is the result of malignant ventricular arrhythmias [i.e., ventricular tachycardia's (VT) and ventricular fibrillation (VF)] [8, 30, 31]. Most often VT is caused by re-entry mechanisms and occurs in the presence of heterogeneous myocardial excitation $[32,33]$. Terai et al. showed that the occurrence of malignant VT in HCM is associated with global cardiac sympathetic activity rather than the heterogeneity of this cardiac sympathetic activity [34]. In this study 44 HCM patients were monitored with ambulatory electrocardiographic monitoring and were assessed with planar and SPECT ${ }^{123} \mathrm{I}-m \mathrm{IBG}$ scintigraphy. 15 patients developed VT, defined as a run of 3 or more consecutive beats at a rate of $\geq 120$ beats/min. WO was significantly increased in the group with VT compared to those without VT $(0.27 \pm 0.06$ vs. $0.17 \pm 0.06, p<0.0001)$. Late $\mathrm{H} / \mathrm{M}$ and regional ${ }^{123} \mathrm{I}$ $m$ IBG parameters from the SPECT images showed no statistically significant difference between the two groups. Although the left ventricular ejection function (LVEF) in patients with VT was decreased compared with those without VT, multiple regression analysis demonstrated that WO was het most powerful predictor of occurrence of VT. The findings of this study suggest that a global rather than regional increase of adrenergic drive (i.e., WO) may increase the heterogeneous conduction of excitation and may easily cause VT in patient with HCM. In addition, in patients with VT the cardiac sympathetic activity is increased probably in response to the impaired $\mathrm{LV}$ dysfunction.

\section{Pathophysiology}

Progression of many clinical features of HCM could be explained by stimulation of increased cardiac sympathetic activity. NE induces myocardial cell growth, disarray and scarring [35-37]. Second, $\alpha$-adrenergic coronary constriction caused by increased NE levels can induce myocardial ischemia [38]. Third, NE increases rate of spontaneous depolarization of myocardial cells, which may predispose to ventricular arrhythmias. Fourth, most HCM patients have an increased global LVEF, indicating increased contractility, which might be due to accelerated cardiac adrenergic activity. Finally, $\beta$-adrenergic blocking agents have shown to be efficient in controlling symptoms in HCM [9].

Studies discussed in the previous section (Table 1) are limited by their single center design with differences in acquisition technique (gamma camera, collimator, acquisition time) and semi-quantitative analysis. These differences have hampered multicentre comparison of the ${ }^{123} \mathrm{I}$ $m$ IBG scintigraphy. The proposal by Flotats et al. to standardize cardiac sympathetic imaging for ${ }^{123} \mathrm{I}-\mathrm{mIBG}$ scintigraphy will most likely reduce the interinstitutional variation [39]. To reduce the interinstitutional variation Nakajima et al. used a cross calibration phantom method, to convert institutional H/M to standardized H/M [40].

\section{Tako-tsubo cardiomyopathy}

TCM, also known as stress-induced cardiomyopathy, apical ballooning syndrome or broken heart syndrome was first described in Japan in 1990 [41]. It is characterized by transient systolic dysfunction of apical and/or mid segments accompanied with ballooning of these segments. Importantly, most often wall motion abnormalities extent beyond the distribution of any single coronary artery. The clinical presentation can mimic acute myocardial infarction, in the absence of obstructive coronary artery disease. The Japanese phrase 'tako-tsubo' can be translated in English as 'octopus pot', a fishing jar with a narrow neck and wide base used to trap an octopus. This description reflects the visual appearance of the heart on left 
Table 1 An overview of the different cardiac ${ }^{123} \mathrm{I}-m$ IBG scintigraphy studies in HCM with the primary study outcome

\begin{tabular}{|c|c|c|c|c|}
\hline \multicolumn{2}{|l|}{ References } & Patients & \multicolumn{2}{|c|}{${ }^{123} \mathrm{I}-m \mathrm{IBG}$ parameters and morphology } \\
\hline \multicolumn{2}{|l|}{ Pace et al. [19] } & $\operatorname{HCM}(n=11)$ & \multicolumn{2}{|c|}{$\begin{array}{l}\text { Late H/M correlates with septal hypertrophy } \\
\text { WO correlates with LVOT obstruction }\end{array}$} \\
\hline \multicolumn{2}{|l|}{ Teria et al. [23] } & $\begin{array}{l}\text { HCM }(n=46) \text { with } 3 \text { categories: } \\
\text { normal LVF, dilated LV, dilated } \\
\text { LV with impaired LVF }\end{array}$ & \multicolumn{2}{|c|}{$\begin{array}{l}\text { WO correlates with impaired LV function in } \\
\text { HCM }\end{array}$} \\
\hline \multicolumn{2}{|l|}{$\begin{array}{l}\text { Matsuo et al. } \\
\text { [24] }\end{array}$} & $\begin{array}{l}\mathrm{HCM}(n=59) \text { and controls } \\
\quad(n=23)\end{array}$ & \multicolumn{2}{|c|}{$\begin{array}{l}\text { Late H/M correlates with BNP and LV mass } \\
\text { WO correlated with plasma NE levels }\end{array}$} \\
\hline References & Patier & & & $\begin{array}{l}{ }^{123} \mathrm{I}-m \mathrm{IBG} \text { parameters and } \\
\text { prognosis }\end{array}$ \\
\hline $\begin{array}{l}\text { Hiase } \\
\text { et al. } \\
{[28]}\end{array}$ & \multicolumn{3}{|c|}{$\begin{array}{l}\text { HCM }(n=84) \text { and controls }(n=18) \text { with three } \\
\text { categories late H/M: }<2.11(n=34), 1.86-2.11 \\
(n=30),<1.86(n=20)\end{array}$} & $\begin{array}{l}\text { Late } \mathrm{H} / \mathrm{M} \text { independent predictor } \\
\text { of onset heart failure }\end{array}$ \\
\hline $\begin{array}{l}\text { Teria et al. } \\
{[34]}\end{array}$ & \multicolumn{3}{|c|}{$\begin{array}{l}\mathrm{HCM}(n=44) \text { with categories VT }(n=15) \text { and no VT } \\
\quad(n=29)\end{array}$} & $\begin{array}{l}\text { Increased WO independent } \\
\text { predictor of ventricular } \\
\text { tachycardia }\end{array}$ \\
\hline
\end{tabular}

ventriculography or echocardiography (Fig. 2). Considerable evidence points to epinephrine as an important factor in the pathophysiology [42]. In the acute phase of TCM, plasma epinephrine levels are more elevated compared with the acute phase of a myocardial infarction [43].

TCM affects predominantly post-menopausal women and is usually preceded by exposure to physical or emotional stress. Major symptoms of TCM are chest pain at rest, mimicking acute myocardial infarction and dyspnea. In general TCM has a favorable prognosis and after the acute phase left ventricular function normalizes in four weeks [43]. The annual recurrent rate of TCM is 1-2\% [44].

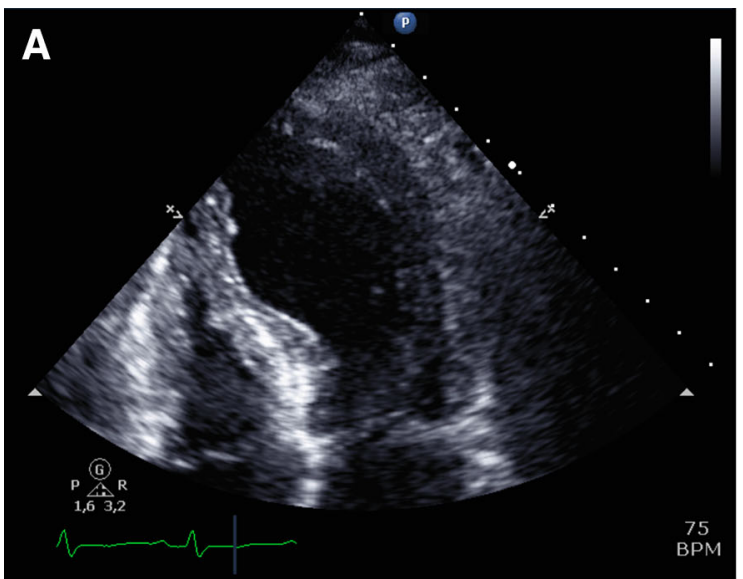

Fig. 2 Examples of Tako-tsubo cardiomyopathy assessed with echocardiography (a) and MRI (b) showing typical apical ballooning with hyperkinesia of the basal segments and dyskinesia of the apical segments of the LV

\section{Tako-tsubo cardiomyopathy and cardiac sympathetic activity}

In the sub-acute phase of TCM ${ }^{123} \mathrm{I}-m \mathrm{IBG}$ scintigraphy reveals impaired apical myocardial uptake of ${ }^{123} \mathrm{I}-m \mathrm{IBG}$ on planar images [45]. This is confirmed by SPECT ${ }^{123} \mathrm{I}-$ $m$ IBG imaging, which demonstrated mainly decreased ${ }^{123} \mathrm{I}$ $m$ IBG uptake of the myocardial apex, which correlates with the impaired LV segments [46, 47]. Akashi et al. confirmed these findings in $8 \mathrm{TCM}$ patients using both planar and SPECT ${ }^{123}$ I- $m$ IBG imaging [48]. Interestingly, 3 months after the onset of TCM the impaired late H/M was significantly increased $(1.89 \pm 0.25$ vs. $2.16 \pm 0.24, p<0.05)$.

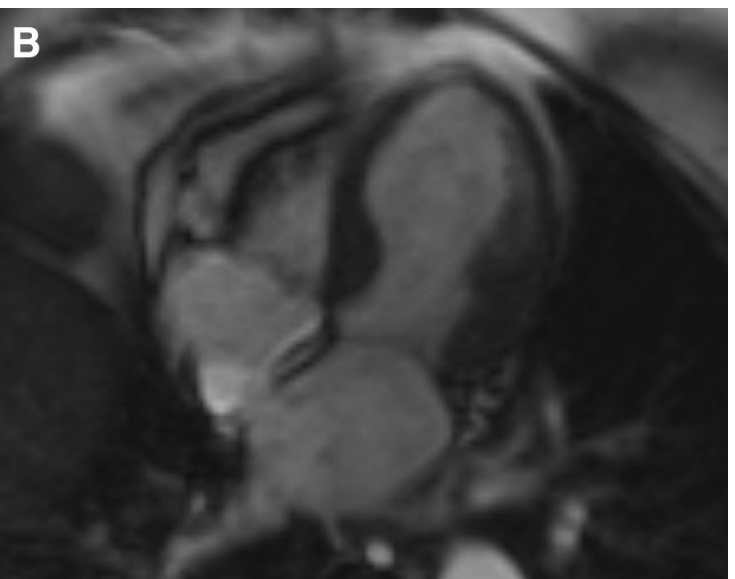


In addition, the WO was significantly decreased $(0.39 \pm 0.10$ vs. $0.25 \pm 0.06, p<0.05)$. The SPECT imaging shows impaired uptake of ${ }^{123} \mathrm{I}-m \mathrm{IBG}$ mainly in the apex and inferior wall both in the sub-acute phase as 3 months after the onset of TCM. These results suggest that TCM could be caused by neurogenic myocardial stunning. Recently, we have reported a possible explanation of impaired regional ${ }^{123} \mathrm{I}-m \mathrm{IBG}$ uptake in TCM [49]. The pattern of impaired ${ }^{123} \mathrm{I}-m \mathrm{IBG}$ uptake follows the increasing $\beta_{2} \mathrm{AR}: \beta_{1} \mathrm{AR}$ ratio from the base to the apex $[42,50]$. In addition to the classical apical ballooning TCM there are several case reports of mid-ventricular ballooning, probably caused by a variation of $\beta_{2} \mathrm{AR}: \beta_{1} \mathrm{AR}$ ratio. Interestingly, it has been reported that in mid-ventricular ballooning SPECT ${ }^{123} \mathrm{I}-m \mathrm{IBG}$ imaging showed impaired uptake of ${ }^{123} \mathrm{I}-m \mathrm{IBG}$ in the mid wall. This underlines our hypothesis that neurogenic stunning occurs in myocardium with increased $\beta_{2} \mathrm{AR}: \beta_{1} \mathrm{AR}$ ratio.

Although left ventricular function and epinephrine levels are normalized after a few weeks, several case reports show a persistent decrease in ${ }^{123} \mathrm{I}-m \mathrm{IBG}$ uptake on SPECT images in the apical myocardium $[46,51]$. The mechanism of this persisting regional impaired ${ }^{123} \mathrm{I}-m \mathrm{IBG}$ uptake is yet unclear. We assume that the increased apical density and sensitivity of the $\beta_{2} \mathrm{AR}$ to epinephrine causes a prolonged effect of downregulation of $\beta_{2} \mathrm{AR}$ and impaired uptake- 1 function (i.e., norepinephrine re-uptake transporter). This causes relatively high levels of epinephrine and NE in the synaptic cleft and may in turn cause these receptors and transporters to recover more slowly compared to more basal located $\beta_{2}$ ARs. In addition, the phenomenon of persisting decreased myocardial ${ }^{123}$ I- $m$ IBG uptake may in part be explained by pre-existing myocardial sympathetic denervation. Of interest is whether especially the slow recovery of apical ${ }^{123} \mathrm{I}-m$ IBG uptake may identify those patients who are at an increased risk of the recurrent TCM.

In conclusion, cardiac ${ }^{123} \mathrm{I}-m \mathrm{IBG}$ scintigraphy can be used to assess cardiac sympathetic activity in primary cardiomyopathies like HCM and TCM.

Cardiac sympathetic activity is increased in HCM and correlates to the septal wall thickness and consequently to the LVOT obstruction. Moreover, increased cardiac sympathetic activity correlates with impaired diastolic and systolic LV function and increased BNP, which is in line with CHF studies [52]. This suggests that increased cardiac sympathetic activity is a result of the unfavorable hemodynamics in HCM. In addition, cardiac ${ }^{123} \mathrm{I}-m \mathrm{IBG}$ scintigraphy may be useful for determining the risk of developing congestive heart failure and ventricular tachycardia in these patients.

${ }^{123}$ I- $m$ IBG scintigraphy can be used to assess cardiac sympathetic hyperactivity in TCM patients who are characterized by neurogenic myocardial stunning. In addition,
${ }^{123}$ I- $m$ IBG scintigraphy may identify those patients who are prone to TCM recurrence and may help to identify responders to individual (pharmacological) therapy.

\section{Compliance with ethical standards}

Grant support None of the authors has been supported by a grant.

Conflict of interest None.

Ethical approval This article does not contain any studies with human participants or animals performed by any of the authors.

Open Access This article is distributed under the terms of the Creative Commons Attribution 4.0 International License (http://crea tivecommons.org/licenses/by/4.0/), which permits unrestricted use, distribution, and reproduction in any medium, provided you give appropriate credit to the original author(s) and the source, provide a link to the Creative Commons license, and indicate if changes were made.

\section{References}

1. Schofer J, Spielmann R, Schuchert A, Weber K, Schluter M (1988) Iodine-123 meta-iodobenzylguanidine scintigraphy: a noninvasive method to demonstrate myocardial adrenergic nervous system disintegrity in patients with idiopathic dilated cardiomyopathy. J Am Coll Cardiol 12(5):1252-1258

2. McGhie AI, Corbett JR, Akers MS, Kulkarni P, Sills MN, Kremers $\mathrm{M}$ et al (1991) Regional cardiac adrenergic function using I-123 meta-iodobenzylguanidine tomographic imaging after acute myocardial infarction. Am J Cardiol 67(4):236-242

3. Wichter T, Hindricks G, Lerch H, Bartenstein P, Borggrefe M, Schober O et al (1994) Regional myocardial sympathetic dysinnervation in arrhythmogenic right ventricular cardiomyopathy. An analysis using 123I-meta-iodobenzylguanidine scintigraphy. Circulation 89(2):667-683

4. Shimizu M, Ino H, Yamaguchi M, Terai H, Hayashi K, Nakajima $\mathrm{K}$ et al (2002) Heterogeneity of cardiac sympathetic nerve activity and systolic dysfunction in patients with hypertrophic cardiomyopathy. J Nucl Med 43(1):15-20

5. Merlet P, Benvenuti C, Moyse D, Pouillart F, Dubois-Rande JL, Duval AM et al (1999) Prognostic value of MIBG imaging in idiopathic dilated cardiomyopathy. J Nucl Med 40(6):917-923

6. Maron BJ, Gardin JM, Flack JM, Gidding SS, Kurosaki TT, Bild DE (1995) Prevalence of hypertrophic cardiomyopathy in a general population of young adults. Echocardiographic analysis of 4111 subjects in the CARDIA study. Coronary artery risk development in (young) adults. Circulation 92(4):785-789

7. Maron BJ, Sato N, Roberts WC, Edwards JE, Chandra RS (1979) Quantitative analysis of cardiac muscle cell disorganization in the ventricular septum. Comparison of fetuses and infants with and without congenital heart disease and patients with hypertrophic cardiomyopathy. Circulation 60(3):685-696

8. Spirito P, Bellone P, Harris KM, Bernabo P, Bruzzi P, Maron BJ (2000) Magnitude of left ventricular hypertrophy and risk of sudden death in hypertrophic cardiomyopathy. N Engl J Med 342(24):1778-1785

9. Spirito P, Seidman CE, McKenna WJ, Maron BJ (1997) The management of hypertrophic cardiomyopathy. N Engl J Med 336(11):775-785

10. Elliott P, McKenna WJ (2004) Hypertrophic cardiomyopathy. Lancet 363(9424):1881-1891 
11. Briasoulis A, Mallikethi-Reddy S, Palla M, Alesh I, Afonso L (2015) Myocardial fibrosis on cardiac magnetic resonance and cardiac outcomes in hypertrophic cardiomyopathy: a meta-analysis. Heart. doi:10.1136/heartjnl-2015-307682

12. Schafers M, Dutka D, Rhodes CG, Lammertsma AA, Hermansen F, Schober O et al (1998) Myocardial presynaptic and postsynaptic autonomic dysfunction in hypertrophic cardiomyopathy. Circ Res 82(1):57-62

13. Li ST, Tack CJ, Fananapazir L, Goldstein DS (2000) Myocardial perfusion and sympathetic innervation in patients with hypertrophic cardiomyopathy. J Am Coll Cardiol 35(7):1867-1873

14. Brush JE Jr, Eisenhofer G, Garty M, Stull R, Maron BJ, Cannon RO 3rd et al (1989) Cardiac norepinephrine kinetics in hypertrophic cardiomyopathy. Circulation 79(4):836-844

15. Nakajima K, Bunko H, Taki J, Shimizu M, Muramori A, Hisada K (1990) Quantitative analysis of 123I-meta-iodobenzylguanidine (MIBG) uptake in hypertrophic cardiomyopathy. Am J Cardiol 119(6):1329-1337

16. Taki J, Nakajima K, Bunko H, Simizu M, Muramori A, Hisada K (1990) Whole-body distribution of iodine 123 metaiodobenzylguanidine in hypertrophic cardiomyopathy: significance of its washout from the heart. Eur J Nucl Med 17(5):264-268

17. Shimizu M, Sugihara N, Kita Y, Shimizu K, Horita Y, Nakajima $\mathrm{K}$ et al (1992) Long-term course and cardiac sympathetic nerve activity in patients with hypertrophic cardiomyopathy. Br Heart $\mathrm{J}$ 67(2): $155-160$

18. Nakajima K, Taki J, Tonami N, Hisada K (1994) Decreased 123IMIBG uptake and increased clearance in various cardiac diseases. Nucl Med Commun 15(5):317-323

19. Pace L, Betocchi S, Losi MA, Della Morte AM, Ciampi Q, Nugnez R et al (2004) Sympathetic nervous function in patients with hypertrophic cardiomyopathy assessed by [123I]-MIBG: relationship with left ventricular perfusion and function. Q J Nucl Med Mol Imaging 48(1):20-25

20. Okayama S, Uemura S, Horii M, Kawata H, Saito Y (2008) Continuing improvement of cardiac sympathetic activity on I-123 MIBG scintigraphy in a patient with hypertrophic obstructive cardiomyopathy after percutaneous transluminal septal myocardial ablation. J Nucl Cardiol 15(5):e31-e34

21. Shimizu M, Ino H, Okeie K, Yamaguchi M, Hayashi K, Nagata $M$ et al (2002) Septal wall thinning and systolic dysfunction in patients with hypertrophic cardiomyopathy caused by a cardiac troponin I gene mutation. Am Heart J 143(4):690-695

22. Horita Y, Shimizu M, Sugihara N, Suematsu T, Shibayama S, Itoh $\mathrm{H}$ et al (1990) An autopsy case of hypertrophic cardiomyopathy showing dilated cardiomyopathy-like features by serial ventriculography. Jpn J Med 29(4):448-453

23. Terai H, Shimizu M, Ino H, Yamaguchi M, Uchiyama K, Oe K et al (2003) Changes in cardiac sympathetic nerve innervation and activity in pathophysiologic transition from typical to end-stage hypertrophic cardiomyopathy. J Nucl Med 44(10):1612-1617

24. Matsuo S, Nakamura Y, Tsutamoto T, Kinoshita M (2002) Impairments of myocardial sympathetic activity may reflect the progression of myocardial damage or dysfunction in hypertrophic cardiomyopathy. J Nucl Cardiol 9(4):407-412

25. ten Cate FJ, Roelandt J (1979) Progression to left ventricular dilatation in patients with hypertrophic obstructive cardiomyopathy. Am Heart J 97(6):762-765

26. McKenna W, Deanfield J, Faruqui A, England D, Oakley C, Goodwin J (1981) Prognosis in hypertrophic cardiomyopathy: role of age and clinical, electrocardiographic and hemodynamic features. Am J Cardiol 47(3):532-538

27. Spirito P, Maron BJ, Bonow RO, Epstein SE (1987) Occurrence and significance of progressive left ventricular wall thinning and relative cavity dilatation in hypertrophic cardiomyopathy. Am J Cardiol 60(1):123-129
28. Hiasa G, Hamada M, Saeki H, Ogimoto A, Ohtsuka T, Hara Y et al (2004) Cardiac sympathetic nerve activity can detect congestive heart failure sensitively in patients with hypertrophic cardiomyopathy*. Chest 126(3):679-686

29. Sipola P, Vanninen E, Aronen HJ, Lauerma K, Simula S, Jaaskelainen $P$ et al (2003) Cardiac adrenergic activity is associated with left ventricular hypertrophy in genetically homogeneous subjects with hypertrophic cardiomyopathy. J Nucl Med 44(4):487-493

30. Maron BJ, Roberts WC, Epstein SE (1982) Sudden death in hypertrophic cardiomyopathy: a profile of 78 patients. Circulation 65(7):1388-1394

31. Elliott PM, Poloniecki J, Dickie S, Sharma S, Monserrat L, Varnava A et al (2000) Sudden death in hypertrophic cardiomyopathy: identification of high risk patients. J Am Coll Cardiol 36(7):2212-2218

32. Gough WB, Mehra R, Restivo M, Zeiler RH, El-Sherif N (1985) Reentrant ventricular arrhythmias in the late myocardial infarction period in the dog. 13. Correlation of activation and refractory maps. Circ res 57(3):432-442

33. Tomaselli GF, Beuckelmann DJ, Calkins HG, Berger RD, Kessler PD, Lawrence JH et al (1994) Sudden cardiac death in heart failure. The role of abnormal repolarization. Circulation 90(5):2534-2539

34. Terai H, Shimizu M, Ino H, Yamaguchi M, Hayashi K, Sakata K et al (2003) Cardiac sympathetic nerve activity in patients with hypertrophic cardiomyopathy with malignant ventricular tachyarrhythmias. J Nucl Cardiol 10(3):304-310

35. Laks MM, Morady F, Swan HJ (1973) Myocardial hypertrophy produced by chronic infusion of subhypertensive doses of norepinephrine in the dog. Chest 64(1):75-78

36. Rapacciuolo A, Esposito G, Caron K, Mao L, Thomas SA, Rockman HA (2001) Important role of endogenous norepinephrine and epinephrine in the development of in vivo pressure-overload cardiac hypertrophy. J Am Coll Cardiol 38(3):876-882

37. Simpson P (1985) Stimulation of hypertrophy of cultured neonatal rat heart cells through an alpha 1-adrenergic receptor and induction of beating through an alpha 1- and beta 1-adrenergic receptor interaction. Evidence for independent regulation of growth and beating. Circ Res 56(6):884-894

38. Baumgart D, Haude M, Gorge G, Liu F, Ge J, Grosse-Eggebrecht C et al (1999) Augmented alpha-adrenergic constriction of atherosclerotic human coronary arteries. Circulation 99(16):2090-2097

39. Flotats A, Carrio I, Agostini D, Le Guludec D, Marcassa C, Schafers M et al (2010) Proposal for standardization of 123Imetaiodobenzylguanidine (MIBG) cardiac sympathetic imaging by the EANM Cardiovascular Committee and the European Council of Nuclear Cardiology. Eur J Nucl Med Mol Imaging 37(9):1802-1812

40. Nakajima K, Okuda K, Yoshimura M, Matsuo S, Wakabayashi H, Imanishi $\mathrm{Y}$ et al (2014) Multicenter cross-calibration of I-123 metaiodobenzylguanidine heart-to-mediastinum ratios to overcome camera-collimator variations. J Nucl Cardiol 21(5):970-978

41. Sato HTH, Uchida T (1990) Takotsubo type cardiomyopathy due to multivessel spasm. In: Kodama K, Haze K, Hon M (eds) Clinical aspect of myocardial injury: from ischemia to heart failure. Kagakuhyouronsya Co, Tokyo, pp 56-64 (in Japanese)

42. Paur H, Wright PT, Sikkel MB, Tranter MH, Mansfield C, O'Gara P et al (2012) High levels of circulating epinephrine trigger apical cardiodepression in a beta2-adrenergic receptor/Gidependent manner: a new model of Takotsubo cardiomyopathy. Circulation 126(6):697-706

43. Wittstein IS, Thiemann DR, Lima JAC, Baughman KL, Schulman SP, Gerstenblith G et al (2005) Neurohumoral features of 
myocardial stunning due to sudden emotional stress. N Engl J Med 352(6):539-548

44. Singh K, Carson K, Usmani Z, Sawhney G, Shah R, Horowitz J (2014) Systematic review and meta-analysis of incidence and correlates of recurrence of takotsubo cardiomyopathy. Int $\mathbf{J}$ Cardiol 174(3):696-701

45. Verberne HJ, van der Heijden DJ, van Eck-Smit BL, Somsen GA (2009) Persisting myocardial sympathetic dysfunction in takotsubo cardiomyopathy. J Nucl Cardiol 16(2):321-324

46. Akashi YJ, Takano M, Miyake F (2010) Scintigraphic imaging in Tako-Tsubo cardiomyopathy. Herz 35(4):231-238

47. Mena LM, Martin F, Melero A, Ramos A, Jimenez IR (2011) Takotsubo syndrome. Usefulness of nuclear medicine studies. Rev Esp Med Nucl 30(2):104-106

48. Akashi YJ, Nakazawa K, Sakakibara M, Miyake F, Musha H, Sasaka K (2004) 123I-MIBG myocardial scintigraphy in patients with "takotsubo" cardiomyopathy. J Nucl Med 45(7):1121-1127

49. Verschure DO, Somsen GA, van Eck-Smit BL, Knol RJ, Booij J, Verberne HJ (2014) Tako-tsubo cardiomyopathy: how to understand possible pathophysiological mechanism and the role of (123)I-MIBG imaging. J Nucl Cardiol 21(4):730-738

50. Lyon AR, Rees PS, Prasad S, Poole-Wilson PA, Harding SE (2008) Stress (Takotsubo) cardiomyopathy - a novel pathophysiological hypothesis to explain catecholamine-induced acute myocardial stunning. Nat Clin Pract Cardiovasc Med 5(1):22-29

51. Moriya M, Mori H, Suzuki N, Hazama M, Yano K (2002) Sixmonth follow-up of takotsubo cardiomyopathy with I-123-betametyl-iodophenyl pentadecanoic acid and I-123-meta-iodobenzyl-guanidine myocardial scintigraphy. Intern Med 41(10):829-833

52. Jacobson AF, Senior R, Cerqueira MD, Wong ND, Thomas GS, Lopez VA et al (2010) Myocardial iodine-123 meta-iodobenzylguanidine imaging and cardiac events in heart failure. Results of the prospective ADMIRE-HF (AdreView Myocardial Imaging for Risk Evaluation in Heart Failure) study. J Am Coll Cardiol 55(20):2212-2221 